DOI 10.37882/2223-2974.2020.10.18

\title{
РАЗРАБОТКА КОМПЛЕКСНОЙ МЕТОДИКИ ОПРЕДЕЛЕНИЯ ИНВЕСТИЦИОННОЙ ПРИВЛЕКАТЕЛЬНОСТИ РЕГИОНАЛЬНЫХ ПРЕДПРИЯТИЙ (ОТРАСЛЕЙ ПРОМЫШЛЕННОСТИ)
}

\section{DEVELOPMENT OF A COMPREHENSIVE METHODOLOGY FOR DETERMINING THE INVESTMENT ATTRACTIVENESS OF REGIONAL ENTERPRISES (INDUSTRIES) \\ D. Malov}

Summary: The article discusses complex methods for assessing investment attractiveness of enterprises in the engineering industry. The strengths and weaknesses of each method are identified, and a cluster method for assessing investment attractiveness of enterprises is proposed. The analysis and ways of further development of this technique are given, the advantages and disadvantages of its use are evaluated. A comparative analysis of investment projects of the Russian machinebuilding market is carried out on the example of industrial enterprises of the Nizhny Novgorod region.

Keywords: cluster, investment attractiveness, estimation, complex analysis, score estimation.

\author{
Малов Дмитрий Николаевич \\ Аспирант, Национальный исследовательский \\ Нижегородский государственный университет \\ им. Н.И. Лобачевского, Нижний Новгород, Россия \\ dnmalov1@yandex.ru
}

Аннотация: В статье рассмотрены комплексные методики оценки инвестиционной привлекательности предприятий отрасли машиностроение. Были выявлены преимущества и недостатки каждой методики, а также предложена кластерная методика оценки инвестиционной привлекательности предприятий. Приведен анализ и пути дальнейшего развития данной методики, оценены преимущества и недостатки ее использования. На примере промышленных предприятий Нижегородской области проведен сравнительный анализ инвестиционных проектов российского рынка машиностроения.

Ключевые слова: кластер, инвестиционная привлекательность, оценка, комплексный анализ, балльная оценка.
$\Pi$ роблема роста инвестиционной привлекательности сектора машиностроение на данном этапе развития является актуальной задачей, поскольку данный сегмент является одним из ключевых элементов экономики России (по данным Федеральной службы государственной статистики, доля Обрабатывающих производств в структуре Валовой добавленной стоимости в 2019 году составила 14,4\%)[1]. От эффективности функционирования данного сегмента зависит успех решения множества социально-экономических задач. Время от времени экономические кризисы вносят корректировки в управление экономическим состоянием предприятий различных отраслей промышленности. При этом, отрасль машиностроение особенно нуждается в своевременных корректировках управления, так как внедрение любых изменений в данной отрасли сопряжено с большим периодом реализации изменений.

Из-за сформировавшейся тяжелой ситуации на рынке спроса, отрасль машиностроение в России показывает тенденцию спада, влекущую снижение объемов производства. Ситуация еще более усугубляется снижением цен на энергоносители, как основного локомотива развития экономики России, а также случившейся пандемией и установлением вынужденных мер по ее ликвидации. Индекс промышленного производства снизился до 98,6\% с января по май 2020 в сравнении с АППГ[2]. Оборот предприятий машиностроения сократился за январь-апрель 2020 году на -2,25\% по сравнению с аналогичным периодом 2019 года - с 14715 млрд руб. до 14382 млрд руб., данные взяты из материалов Федеральной службы государственной статистики. Данная тенденция спада промышленного производства плохо влияет на инвестиционную привлекательность предприятий машиностроения [3].

В целях обеспечения растущего интереса иностранных инвесторов к акциям российских производственных предприятий необходимо повышать уровень их инвестиционной привлекательности и создавать устойчивую отраслевую структуру на долгосрочную перспективу. В развитии отрасли машиностроение растет значение правильного выбора приоритетных направлений инвестиционной деятельности.

В настоящее время перед экономистами актуально стоят вопросы обеспечения высоких темпов стабильного роста и увеличения конкурентоспособности на всех потенциальных нишах за счет повышения производительности труда на предприятиях. По данным Министерства экономического развития, для обеспечения роста ВВП России до уровня 3\% необходим производи- 
тельности труда предприятий не менее чем на 5\% (для этой цели был запущен национальный проект «Производительность труда и поддержка занятости»)[4]. Достичь такого уровня роста промышленного производства можно только в случае согласованной работы всей отрасли промышленности. Для более оптимального распределения ресурсов и быстрой оценки нужд того или иного предприятия, имеет место процесс образования и формирования кластеров. Именно кластеры могут быть «точками роста» экономики регионального и федерального уровней. С одной стороны, кластеры как самостоятельные единицы могут существовать отдельно друг от друга, регулируя использование производственных мощностей в зависимости от потребностей заказчиков. С другой стороны, кластеры могут исполнять функции межотраслевых комплексов, тем самым помогая друг другу решить ту или иную производственную задачу и повысить инвестиционную привлекательность производственного направления или конкретного предприятия.

Существует большое количество методов в анализе и оценке инвестиционной привлекательности предприятий, каждый из которых обладает своими достоинствами и недостатками. Изучением данных методов занимались современные российские ученые, такие как: Т.З. Ахмятжанов, В.В. Мазаев, Т.В. Ковалёва, А.А. Шапошников, О.И. Гаврилюк, Е.Н. Староверова, Е.Н. Летягина, Н. Лысенко, В.А. Лацинников, Ю.В. Патрикеева.

Основоположниками анализа инвестиционной привлекательности предприятий: на базе организационных, технических и социальных условий производства, качества менеджмента и рыночной среды считается И.А. Михалева, на основе связи дохода и риска - У. Шарп, интегральную 3D-модель как результат реакции величин привлекательности предприятия, региона, отрасли использует Н.Н. Буреева[6]. Из этого многообразия выделяется кластерный анализ, который рассматривается авторами как дополнение для их основной модели. Авторы ставят перед собой задачу более глубоко проанализировать кластерный анализ и восполнить возникшие пробелы в данном вопросе.

Метод, описанный в [7], предлагает оценить сравнительную и совершенную привлекательность:

- совершенная инвестиционная привлекательность предполагает анализ конкретного инвестиционного проекта и является позитивной, при массе прибыли за весь амортизационный цикл, равной «нулю»;

- сравнительная инвестиционная привлекательность берет за основу соотнесение со среднеотраслевой инвестиционной привлекательностью, или с прочими предприятиями отрасли, или с обусловленными нормативными значениями.
Оценка инвестиционной привлекательности в некоторых исследованиях основывается на расчете одного интегрального показателя. Например, в исследовании Н.Н. Буреевой [5] показано, что использование одного показателя дает следующие преимущества:

- возможность сопоставления уровня инвестиционной привлекательности разных предприятий и предпочтения оптимальной вариации инвестирования для инвестора из набора альтернатив;

- возможность учитывать 8 показателей в совокупной оценке;

- возможность сведения количественных и качественных показателей в совокупную оценку.

Многие российские эксперты рекомендуют применение методики Л.В. Донцовой и Н.А. Никифоровой [8], суть которой состоит в группировке предприятий по степени риска исходя из реального уровня финансовой устойчивости и рейтинга, выраженного в баллах. По результатам такой оценки проводится анализ деятельности предприятия в целом, устанавливаются факторы, которые оказывают позитивное и негативное воздействие на результаты деятельности, разрабатываются вариации оптимальных управленческих решений.

Еще одним из популярных методов считается спектр балльного метода. Основная суть данного метода состоит в том, что проведение анализа финансовых коэффициентов промышленного предприятия происходит путем сравнения полученных значений с рекомендуемыми нормативными величинами. Чем ниже значения коэффициентов от нормы, тем хуже финансовое состояние предприятия и наоборот.

Образованию кластеров содействует активное развитие регионов и углубление межрегиональной интеграции. Существование базы позитивных эффектов, которые формируют их относительные достоинства, считается главной особенностью кластера. К ним можно отнести:

- эффект размаха производства, в основу которого входит наличие костяка инновационной активности на лидирующем предприятии кластера;

- эффект масштаба, который возникает при наличии многопродуктового фактора производства. Этот эффект увеличивается при помощи классификации предприятий, а также при минимумах транзакционных издержек зарождается возможность применения разных факторов производства;

- эффект синергии, в основу чего входит оптимальный синтез компонентов системы, которые определяют эффективность и качество реакции[7].

При объединении трех эффектов кластера в целом возникают дополнительные преимущества и конкурент- 
ные возможности. К примеру, предприятия на грани банкротства получают возможность выйти в положительную динамику при помощи специализации, которая обеспечивает понижение себестоимость товаров и рост производительности труда.

Кроме этих трех эффектов существует эффект мультипликатора, считающийся основным показателем деловой активности и успешности кластера. При этом эффект мультипликатора снижается, если производимые товары завозятся из другого региона. Кроме этого, на уровень эффекта мультипликатора воздействует географическое положение, выявляющего особенности в развитости эффект мультипликатора:

- экономическая скрытность;

- экономическое постоянство;

- развитость региональной экономики;

- успешность экономики региона. [9]

Отсюда следует, что привлечение инноваций содействует проявлению эффекта мультипликатора в развитии кластера и в экономике региона.

Эффект блокировки предприятий в составе кластера появляется в случаях, когда у него низкая конкурентоспособность, в отличие от предприятия вне состава кластера. Тут стоит обратить повышенное внимание на общее развитие кластера.

К недостаткам кластеров можно отнести:

- кооперация предприятий кластера, вызывает сокращение конкурентного давления, что в итоге приводит к ослаблению движущей силы инноваций;

- привыкнув к прошлым успехам, кластер не видит новые направления развития;

- односторонняя специализация кластеров приводит к незащищенности региона, а технологический перерыв сводит на нет отдельные преимущества кластера;

- имеющиеся бескомпромиссные кластерные структуры обладают возможностью увеличить риски приостановки радикальной переориентации [9].

Рассмотрим метод кластерного анализа в секторе машиностроения. Сегодня промышленная сфера экономики России представлена системой отраслевого кластера, в основу которой входят вертикально-интегрированные компании (ВИНК) - это большие холдинги, которые обладают полным производственным циклом - начиная от проектирования, производства комплектующих и, заканчивая сбытом готовой продукции. К таким предприятиям можно отнести: Соллерс, КАМАЗ, ЗМЗ, ПАЗ, Гидроагрегат, ГАЗ, Вертолеты России, которые образовались в ходе приватизации в период 1990-2000 гг.
Особенностями деятельности отраслевого кластера ВИНК считаются его преимущества:

- огромные объемы выработки производства, позволяющие понижать траты на единицу произведенной продукции, чему способствует нахождение рынков сбыта, в т.ч. международных;

- большие производственные мощности, которые обеспечиваются в том числе производственными площадями, а также оборудованием и станками, что способствует сокращению затрат на постоянное расширение производства;

- Реально монопольное положение ВИНК в отдельных регионах и свободный доступ к транспортной инфраструктуре;

- Государственная власть оказывает значительную поддержку ВИНк;

- ВИНК в России стремится занять господствующую роль на российском рынке, вытесняя тем самым зарубежных конкурентов, а также выйти на мировой рынок[10].

Международная экспансия позволит диверсифицировать государственные риски и откроет перед промышленными предприятиями новые возможности[10]. ВИНК зачастую формируют региональные монополии с подавлением местного малого и среднего бизнеса. Из этого следует, что формирование межотраслевого кластера в сфере машиностроения позволяет создавать объединения вертикально-интегрированных компаний с малым и средним бизнесом, которые находятся неподалеку от промышленных предприятий и обслуживающих их производственную деятельность [10].

Главными особенностями межотраслевого кластера в сфере машиностроения считаются [11]:

- в межотраслевой кластер входят предприятия, объединяющиеся на базе соглашений и по территориальному признаку, дающие возможность для развития малых нефтяных компаний. Это позволяет изучать и разрабатывать большое число труднодоступных залежей, совершенствовать сервис обслуживающих предприятий и повышать конкурентоспособность региона, следствием чего будет выведение региона на высокий уровень;

- эффективность работы межотраслевого кластера достигается с помощью эффекта синергии. Результатом чего считается формирование новых предприятий, рост инвестиций, рост экспорта, усиление конкурентоспособности, формирование инфраструктуры, развитие новых технологий, производительности членов кластера, созревание близких связей между производством и наукой, рост уровня образования кадров и увеличение персонала и качества нефтепродуктов;

- большое число участников межотраслевого кластера представляют собой действующие пред- 
приятия или компании.

Оценка эффективности их деятельности предполагает:

1. модификацию итогов эксплуатации функционирующих добывающих и производственных мощностей, возможности опытных, конструкторских, научных и исследовательских учреждений;

2. открытие новых дорог для вливания фактических инвестиций, которые возникают вследствие развития межотраслевого кластера;

- географическое местоположение и близость. Главные члены межотраслевого кластера производственной сферы скапливаются недалеко друг от друга и активно взаимодействуют. В качестве индикаторов местоположение применяются различные показатели, которые характеризуют высокий уровень специализации региона;

- обширный комплект участников и существование «критической массы». Межотраслевой кластер состоит из предприятий-производителей продукции либо услуг, экспортируемых за пределы страны, системы поставщиков оснащения, и ВУЗов, НИИ и прочих поддерживающих учреждений. В качестве индикаторов применяются показатели, которые оценивают высокую степень занятости, число предприятий;

- существование взаимных связей и реакции между участниками межотраслевого кластера [11].

Информационным оснащением изыскания послужила статистическая отчетность сектора Машиностроение Нижегородской области. Данный регион одним из первых в России начал исследование и применил кластерный метод в управлении региональным развитием. Суть метода заключается в управлении данными при принятии эффективных решений на крупных предприятиях рассматриваемого региона с диверсифицированной экономикой, высоким скоплением обрабатывающих производств и мощными научными, инновационными возможностями. Сегодня кластерные инициативы составляют базу развития индустриальной основы России и реализуют конкурентные достоинства промышленных регионов.

При полном анализе инвестиционной привлекательности предприятий применялись подходы многомерного статистического кластерного анализа. Для экономических и математических расчетов была использована компьютерная программы STATISTICA 13.3, StatSoft[5]. Программа считается универсальной средой для работы, включающей в себя методы статистического анализа, многомерных и непараметрических методов анализа. Программа подходит для решения любых задач, которые встречаются в исследованиях качества жизни и позволяет моделировать процессы кластерного анализа.
С точки зрения реализации, достоинством кластерного анализа считается возможность разделения объектов на ряд признаков. Алгоритм этого анализа делится на неиерархический и иерархический. В приведенном исследовании применен иерархический алгоритм анализа, заключающийся в последовательном разделении/объединении групп частей сначала ближайших по сроку, а следом - более удаленных [5].

На сегодняшний день за развитие кластерной системы принялись всерьез. В июне 2020 года Правительство утвердило Стратегию развития обрабатывающей промышленности до 2035 года, в которой явно указано, что ускоренное внедрение инноваций возможно в случае синхронизированного развития индустриальных парков, промышленных кластеров и промышленных технопарков с учетом потенциального трафика. Особое внимание на современном этапе развития производства уделяется высокому уровню межотраслевой кластеризации. В Стратегии определены приоритетные межотраслевые направления развития, такие как:

- энергетика и окружающая среда;

- продовольственная безопасность;

- транспорт и логистическая инфраструктура;

- здравоохранение;

- новые материалы (включая новые технологии в области химии);

- технологии производства и автоматизации;

- микроэлектроника и связь.

Если говорить о региональном развитии и конкретно Нижегородской области, отрасль машиностроение занимает больше 1/3 экономических возможностей Нижегородского региона. В Нижегородской области сконцентрированы крупные производители, занимающие высокие рейтинговые позиции на рынках высокотехнологической продукции. В регионе находятся отраслевые вузы и институты, считающиеся ведущими центрами образования РФ в области технологий машиностроения.

Центральным звеном, объединяющего нижегородские предприятия кластера технологии производства и автоматизации, является Горьковский автомобильный завод (ГАЗ). Также в Нижегородской области расположены крупные машиностроительные предприятия: Гидромаш, Гидроагрегат, Павловский автобусный завод (ПАЗ), Завод имени Кирова, Алмаз Антей, Нител.

Для того, чтобы проанализировать эффективность работы предприятий и сравнить полученные значения между собой, необходимо вычислить показали каждого предприятия в абсолютных величинах. В качестве рассчитываемых показателей могут быть использованы следующие:

- трудовой капитал;

- коэффициенты самоуправления, финансирова- 
ния, абсолютной и текущей ликвидности, рентабельности собственных активов и капитала;

- операционная рентабельность;

- производительность труда;

- фондоотдача;

- оборачиваемость собственного капитала и кредиторской задолженности.

Полученные показатели являются ненормированными, следовательно их нельзя сопоставлять и получать адекватные оценки. Для получения корректного результата, необходимо провести нормировку полученных значений.

Применим способ нормирования: $\mathrm{R}_{\mathrm{n}}=(\mathrm{Ri}-\mathrm{Rmin}) /$ (Rmax - Rmin),

где $\mathrm{Rn}$ - значение нормы изучаемого показателя;

$\mathrm{Ri}$-реальное значение изучаемого показателя;

Rmin - наименьшее значение изучаемого показателя;

$\mathrm{Rmax}$ - предельное значение изучаемого показателя.

После такого преобразования все значения коэффициентов занимают диапазон [0 - 1]. [5]

\section{$\triangle$ Анамика развития машиностроения Нижегородской области}

В настоящее время активно формируется промышленный кластер Нижегородской области. Крупнейшей отраслью промышленности является обрабатывающая промышленность, которая занимает более 30\% валового регионального продукта области (данные за 2016 год). Если говорить о физическом объеме, то его рост по обрабатывающей промышленности за последние 5 лет, с 2014 по 2019 гг. составил 3.3\%, что выше на 1,2 п.п. по сравнению со средним значением по регионам Российской Федерации.

Касаемо структуры отраслей обрабатывающих производств Нижегородской области, можно отметить их значительную диверсификацию: 26\% в общем объеме отгрузки занимает производство нефтепродуктов, металлургия - 14\%, машиностроение - 13\%, атомная промышленность - 11\%, химия и нефтехимия - 7\%, пищевое производство - 7\%, наукоемкое производство - 5\%.

В Нижегородской области созданы и активно работают несколько индустриальных кластеров: промышленный, легкой промышленности, ИТ кластер и два инновационных кластера, а также два индустриальных парка - АО «Заволжский моторный завод» и «Ока»-полимер.

Несмотря на позитивную динамику развития промышленности и создания региональной законодательной базы в целях осуществления поддержки инвестиционных проектов, регион сталкивается со многими сложностями развития, а также в неопределенности по работе в долгосрочной перспективе. Начиная с 2014 года произошло существенное снижение инвестиций в основной капитал, и только в 2017-2018 гг. можно наблюдать некоторое восстановление объема инвестиций до уровня 2012 года[12]. Уровень изношенности основных фондов по обрабатывающим производствам на конец 2017 года составлял 52\%. Правительство региона в 2018 году оказывало активную поддержку предприятиям области в получении инвестиций из Фонда развития промышленности, за этот период сумма займов составила 2,2 млрд рублей в 11 проектов.

Особо стоит отметить показатель стоимости электроэнергии на оптовом рынке, с июля 2016 года она составляла не менее 2730 рублей за МВт-ч. Данное значение на порядок выше чем в сопоставимых регионах - Самарской области (2 405 рублей), Свердловской области (1 869 рублей) и республики Татарстан (2 329 рублей). Текущая стоимость электроэнергии на оптовом рынке является одной из самых высоких в России. Это увеличивает себестоимость промышленной продукции Нижегородской области и сильно снижает ее конкурентоспособность.

Регион активно развивает производство и наращивает объемы отгрузки инновационной продукции. В сравнении с большинством регионов Российской Федерации, объем отгрузки находится на уровне выше среднего значения по регионам. Однако с 2014 года темп роста объемов отгрузки существенно замедлился - с 33\% в 2014 году до 4\% в 2016 и 3\% в 2017 году[13]. Если сравнивать долю инновационной продукции с регионами-бенчмарками, то в Нижегородской области показатель составляет 16,5\%, в республике Татарстан - 19,6\%, в Самарской области - 17,7\%.

Как результат, Правительством Нижегородской области выделены приоритеты развития региона. Перечисленные отрасли являются перспективными для привлечения инвестиций. В первую группу приоритетного развития входят: автомобиле и автобусостроение, информационные технологии, химико-фармацевтическая промышленность, радиоэлектронная промышленность и приборостроение. Ко второй группе относятся: нефтехимическая промышленность, туризм, стекольная промышленность, авиастроение, топливная промышленность, черная металлургия. Если говорить о третьей группе, то к ней относятся: медицинская промышленность, легкая промышленность, промышленность строительных материалов, лесопромышленный комплекс и целлюлозно-бумажная промышленность, судостроение, сельское хозяйство.

В общем, промышленная индустрия Нижегородской области располагает важным потенциалом при реализа- 
ции комплексной Стратегии развития экономики России.

Если рассматривать промышленный сектор в целом, В настоящее время он характеризуется замедлением производства ввиду изношенности основных фондов, повышением конкуренции, снижением производительности труда на фоне пандемии, усложнением производственных процессов.

Остановимся на сильных сторонах промышленного сектора, к ним относятся: интегрированность и ассортимент портфеля продукции, которую производят в регионе, развитая структура обрабатывающих производственных предприятий.

К слабым сторонам промышленного сектора относятся: высокие тарифы на все виды перевозок, высокие тарифы на электроэнергию, высокая степень амортизации оборудования по сопоставлению с мировыми компаниями и применение устаревших технологий производства, невысокий размах производительных мощностей, невысокая ресурсная и энергетическая эффективность.

Главным потенциалом развития отрасли считается наличие обширного ассортимента продуктов с возмож- ностью к импортозамещению, высокими темпами роста рынка и добавленной стоимостью. В основном потенциал формирования промышленного производства заключается в сохранении и увеличении масштабов экспорта, производство сложной продукции и оснащение ее потребления на внутреннем рынке.

К прочим возможностям развития промышленного производства можно отнести рост сложности применяемых основных фондов, вероятный рост внутреннего рынка и получение государственной поддержки отрасли в рамках единой стратегии развития.

В заключение отметим, что одним из главных факторов успешности в развитии межотраслевого кластера промышленной отрасли считается присутствие инициативных связей и увязки усилий между участниками кластера. Эти связи имеют различную природу, включая формализованные связи между главным предприятием и поставщиками, между поставщиками, партнерство с поставщиками запчастей, оборудования и обслуживанием; связи между компаниями, вузами и НИИ в рамках сотрудничества в осуществления общих научных, исследовательских и образовательных проектов[11].

1. https://www.gks.ru/accounts

2. https://gks.ru/enterprise_industrial

3. Финансовые счета и балансы финансовых активов и обязательств системы национальных счетов Российской Федерации - [Электронный ресурс]. Режим доступа: http://www.cbr.ru/statistics/macro_itm/fafbs/ (дата обращения 30.06.2020)

4. https://www.economy.gov.ru/material/directions/nacionalnyy_proekt_proizvoditelnost_truda_i_podderzhka_zanyatosti/

5. http://static.government.ru/media/files/Qw77Aau610SEluQqYnvR4tGMCy6rv6Qm.pdf

6. Буреева Н.Н. Многомерный статистический анализ с применением ППП “STATISTICA”. Учебно-методический материал по программе повышения квалификации «Применение программных средств в научных исследованиях и преподавании математики и механики». - Н.Новгород, 2017. - 112 с.

7. Мелай Е.А., Сергеева А.В. Подходы к оценке инвестиционной привлекательности организации: сравнительный анализ // Известия Тульского государственного университета. Экономические и юридические науки. $-2015 .-$ с.80

8. Донцова Л.В., Никифорова Н.А. Анализ финансовой отчетности. М., 2005.

9. Третьяк В.П. «Кластеры предприятий как форма квазиинтеграции». - [Электронный ресурс]. - Режим доступа: www.znanie.org/FLG/Tretyak/Prezen21_10. ppt. (дата обращения 13.04.2020)

10. Корякина Н.В. Кластеры как способ повышения инвестиционной активности промышленных предприятий региона // Вестник РГГУ. Серия «Экономика. Управление. Право.». - 2012. - с.87.

11. Юсупов К.Н., Янгиров А.В. Межотраслевые комплексы и кластеры в экономике региона // Известия Байкальского государственного университета. 2018. - c.694

12. www.gks.ru/new_site/business/invest/invest_sub

13. http://nizhstat.old.gks.ru/wps/wcm/connect/rosstat_ts/nizhstat/ru/statistics/enterprises/science/

() Малов Дмитрий Николаевич (dnmalov1@yandex.ru).

Журнал «Современная наука: актуальные проблемы теории и практики» 